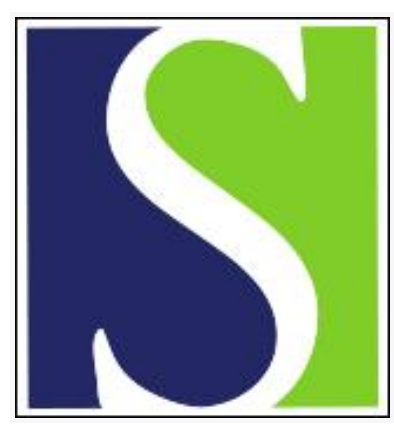

Scand J Work Environ Health 1998;24(4):285-292

https://doi.org/10.5271/sjweh.322

Issue date: Aug 1998

Occurrence of carpal tunnel syndrome among slaughterhouse workers

by Frost P, Andersen JH, Nielsen VK

The following articles refer to this text: 2009;35(1):19-36;

2013;39(5):495-505

Key terms: carpal tunnel release; hand intensive work; historical cohort; neurophysiology

This article in PubMed: www.ncbi.nlm.nih.gov/pubmed/9754860

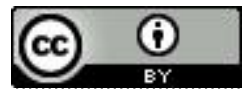




\title{
Occurrence of carpal tunnel syndrome among slaughterhouse workers
}

\author{
by Poul Frost, MD, ${ }^{1}$ Johan Hviid Andersen, PhD, ${ }^{2}$ Viggo Kamp Nielsen, DMedSc ${ }^{3}$
}

\author{
Frost $\mathrm{P}$, Andersen $\mathrm{JH}$, Nielsen VK. Occurrence of carpal tunnel syndrome among slaughterhouse workers. Scand \\ J Work Environ Health 1998;24(4):285-292.
}

\begin{abstract}
Objectives The aim of this study was to examine the risk of carpal tunnel syndrome (CTS) among workers with daily occupational exposure to high-force and high-velocity manual work.

Methods The study was carried out retrospectively among a cohort of 1591 workers employed at a slaughterhouse or at a chemical factory; 1141 persons (71.7\%) participated. Workers not doing tasks in slaughtering or meat processing constituted the reference group. Exposure assessments were made for 46 different tasks in slaughtering and meat processing from video-based observations at the workplace. CTS was diagnosed if there were current symptoms typical of CTS in combination with positive neurophysiological signs of CTS or if the subject had previously been operated on for CTS.

Results Altogether $1.6 \%$ of the reference group, $5.1 \%$ of the nondeboning slaughterhouse workers [prevalence ratio (PR) 3.23, 95\% confidence interval (95\% CI) 1.30-7.99] and 7.8\% of the deboning slaughterhouse workers (PR 4.91,95\% CI 2.03-11.81) had CTS. Increased risk estimates persisted after adjustment for other potential risk factors by logistic regression. The prevalence of CTS in the dominant hand was equally increased in both groups of slaughterhouse workers (but only statistically significant for the workers in deboning tasks), while the prevalence of CTS in the nondominant hand was significantly increased only among the slaughterhouse workers in deboning tasks.

Conclusions This study supports the hypothesis that daily high-velocity and high-force manual work is a risk factor for CTS.
\end{abstract}

Key terms carpal tunnel release, hand intensive work, historical cohort, neurophysiology.

Carpal tunnel syndrome (CTS) is caused by entrapment of the median nerve passing through the carpal tunnel. Cardinal symptoms, although not specific, are tingling and numbness at night in the area of the hand supplied by the median nerve. Impaired function of the nerve across the tunnel can be measured, and it helps establish a more precise diagnosis. Anthropometric characteristics such as body mass index (1), gender (2), and certain diseases (eg, diabetes, thyroid diseases and rheumatoid arthritis) are suggested risk factors for CTS. Occupational exposure to repetitive forceful wrist movements $(3-5)$ and hand-arm vibration (6) have also been associated with CTS. Based on the epidemiologic evidence linking occupational wrist exposure and CTS and plausible physiopathological pathways, independent reviews $(3,4)$ and a meta-analysis (5) have concluded that job tasks involving repetitive forceful movements at the wrist are probably associated with the development of CTS. Recently a Canadian register study found a substantial proportion of
CTS cases attributable to manual work (7). However, the studies considering occupational risk factors for CTS used different measures of both exposures and outcome. Therefore, it is difficult to draw a conclusion about occupational risk factors for CTS on the basis of the existing epidemiologic studies. In order to evaluate the hypothesis that repetitive and forceful manual work is a risk factor for CTS, we studied the occurrence of CTS in a historical cohort consisting of 743 slaughterhouse workers, exposed to manual stress throughout the workday, and 398 repairmen or chemical workers, supervising automatic processes, as the exposure contrast.

\section{Subjects and methods}

The project was a retrospective study of a cohort (8) of workers employed between 1 January 1986 and 30 September 1993 at a slaughterhouse and a chemical

1 Department of Occupational Medicine, Aarhus University Hospital, Aarhus, Denmark.

2 Department of Occupational Medicine, Herning Hospital, Herning, Denmark.

3 Department of Neurophysiology, Aarhus University Hospital, Aarhus, Denmark.

Reprint requests to: Dr Poul Frost, Department of Occupational Medicine, Aarhus University Hospital, Noerrebrogade 44, 02 C, DK-8000 Aarhus C, Denmark. [e-mail: AKH.GP22S.AKAMKPF1@aaa.dk] 
factory in Denmark. Information on duration of employment, together with the personal identification number of the subjects, was obtained from company files. The personal identification number contains information on date of birth and gender. By register linkage to the Danish Central Personal Register, vital status and current postal address were obtained. In all, 1591 subjects still alive and living in Denmark with at least 6 months of seniority within the chosen time period were identified and thus constituted the study population. Of these persons, 1115 were identified at the slaughterhouse and 476 at the chemical plant. Their mean age was 40.5 (SD 12.2) years. Their mean duration of employment was 9.1 (SD 7.6) years, and $14.8 \%$ were women.

Information on exposure and health was collected from a postal questionnaire, ergonomic observation of job tasks, and standardized physical and neurophysiological examinations. There were 832 workers $(74.6 \%)$ from the slaughterhouse with a mean duration of employment of 8.8 (SD 7.2) years. A total of 309 workers $(64.9 \%$ ) from the chemical factory responded to the questionnaire. Their mean duration of employment was 11.3 (SD 8.3) years. Ninety-nine workers from the slaughterhouse had not worked in pig slaughtering or meat processing tasks and were included in the reference group, while 10 workers from the chemical factory had been slaughter-

Table 1. Distribution of age, gender and other characteristics with possible influence on the prevalence of carpal tunnel syndrome among the referents and slaughterhouse workers. (BMI = body mass index)

\begin{tabular}{|c|c|c|c|c|}
\hline \multirow[t]{2}{*}{ Characteristic } & \multirow{2}{*}{$\begin{array}{c}\text { Referents } \\
(\mathrm{N}=398) \\
\%\end{array}$} & \multicolumn{3}{|c|}{ Slaughterhouse workers } \\
\hline & & $\begin{array}{c}\text { Non- } \\
\text { deboning } \\
\text { workers } \\
(\mathrm{N}=397) \\
\%\end{array}$ & $\begin{array}{c}\text { Deboning } \\
\text { workers } \\
(\mathrm{N}=346) \\
\%\end{array}$ & $\begin{array}{c}\text { All } \\
\text { workers } \\
(\mathrm{N}=743 \\
\%\end{array}$ \\
\hline Out of work ${ }^{a}$ & 25.1 & 24.6 & 20.2 & 22.5 \\
\hline $\begin{array}{l}\text { Age } \\
\text { < } 35 \text { years } \\
35-49 \text { years } \\
\geq 50 \text { years }\end{array}$ & $\begin{array}{l}31.4 \\
43.2 \\
25.4\end{array}$ & $\begin{array}{l}31.2 \\
39.3 \\
29.5\end{array}$ & $\begin{array}{l}45.1 \\
40.5 \\
14.5\end{array}$ & $\begin{array}{l}37.7 \\
39.8 \\
22.5\end{array}$ \\
\hline $\begin{array}{l}\text { Wrist trauma } \\
\text { Dominant hand } \\
\text { Nondominant hand } \\
\text { Both hands }\end{array}$ & $\begin{array}{l}4.8 \\
3.3 \\
6.8\end{array}$ & $\begin{array}{l}4.8 \\
4.3 \\
7.8\end{array}$ & $\begin{array}{l}3.2 \\
6.9 \\
8.7\end{array}$ & $\begin{array}{l}4.0 \\
5.5 \\
8.2\end{array}$ \\
\hline $\begin{array}{l}\text { BMI } \\
<25 \mathrm{~kg} / \mathrm{m}^{2} \\
25-29 \mathrm{~kg} / \mathrm{m}^{2} \\
\geq 30 \mathrm{~kg} / \mathrm{m}^{2} \\
\text { Missing data }\end{array}$ & $\begin{array}{r}52.3 \\
36.9 \\
10.8 \\
2.8\end{array}$ & $\begin{array}{r}52.9 \\
35.3 \\
11.8 \\
2.0\end{array}$ & $\begin{array}{r}51.2 \\
41.3 \\
7.5 \\
2.0\end{array}$ & $\begin{array}{r}52.1 \\
38.1 \\
9.8 \\
2.0\end{array}$ \\
\hline $\begin{array}{l}\text { Smoking } \\
\text { Ever smoked } \\
\text { Missing data }\end{array}$ & $\begin{array}{r}78.9 \\
1.5\end{array}$ & $\begin{array}{r}76.8 \\
0.5\end{array}$ & $\begin{array}{r}73.1 \\
1.7\end{array}$ & $\begin{array}{r}75.1 \\
1.1\end{array}$ \\
\hline Medical condition & 8.3 & 7.1 & 4.9 & 6.1 \\
\hline Women & 12.6 & 22.4 & 10.4 & 16.8 \\
\hline
\end{tabular}

a Not at work for at least 3 months prior to the study start.

- Answered yes to the question: have a doctor ever told you, that you suffered from either rheumatic arthritis, diabetes, myxedema or a connective tissue disease? house workers earlier and were thus classified as slaughterhouse workers. The participation rate differed among the subjects from the 2 companies, but a short telephone interview with 50 nonparticipants from the chemical factory and 67 from the slaughterhouse revealed no major differences in the prevalence of prolonged symptoms in the neck and upper extremities of the nonparticipants in comparison with the participants from the 2 companies. Table 1 shows the distribution of background factors and potential risk factors for CTS in the study population.

\section{Exposure assessment}

Information on present and former employment, actual employment status, tasks held at the slaughterhouse, and self-reported ergonomic exposures (9) was obtained from the questionnaire. Main exposure categories (ie, slaughterhouse workers or referents) were defined according to whether the participants had ever worked in tasks entailing pig slaughtering or meat processing. The organization of these processes is described in table 2, together with an observational description of the wrist exposures. The ergonomic observations were based on analyses of video recordings of the right wrist during work. These observations were used to obtain information on the extent to which the tasks actually implied repetitive movements of the wrist and to estimate the proportion of time the wrist was held in nonneutral positions. Video recordings concerning tasks on the killing floor (15 of 17 tasks in the clean end), cutting floor (10 of 18 tasks), packing room ( 5 of 6 tasks), and the casing room (15 of 21 tasks) were obtained at the actual slaughterhouse. Forty-eight recordings of wrist exertion during deboning were obtained at other similar slaughterhouses by the same observers as part of a study of physiological parameters in deboning work in Danish slaughterhouses (10). The organization of the deboning procedures did not differ from what was seen in the slaughterhouse in our study. The tasks observed represented about $90 \%$ of the total jobs at the slaughterhouse. The video recordings were made from 2 positions to register frequencies of dorsal and palmar flexion and ulnar deviation. The frequency of movements substantially out of neutral position (ie, greater than 15 degrees in dorsal or palmar flexion and greater than 20 degrees in ulnar deviation), as well as the duration of wrist positions out of neutral in the same directions, was obtained. Since functional movements at the wrist may overlap, especially in palmar or ulnar and dorsal or ulnar directions, only the direction with the greatest frequency and proportion of time out of neutral position was used (table 2). Tasks at the chemical factory consisted primarily of supervising and simple computer programming of the automatic production of vegetable oil products. No observations of wrist exertion were made at the chemical factory, but the proportion reporting that their task implied several repetitive manual movements 
each minute for more than half the workday was $17 \%$ in the reference group and between $69 \%$ and $93 \%$ among the slaughterhouse workers in the 5 different departments.

\section{Health assessment}

The a priori criteria defining CTS were either (i) a combination of symptoms, occurring at least 1 night a week, indicating entrapment of the median nerve reported via the questionnaire (screening positive) and current symptoms involving at least 1 of the 3 radial fingers in a physical examination (physical examination positive) and positive neurophysiological criteria of CTS or (ii) previous operation for CTS $(\mathrm{N}=24)$. Due to a delay of 2 to 3 months between the questionnaire screening and the physical examination, it was considered important to evaluate a questionnaire-negative group in the physicalexamination group.

The participation in the case identification procedure and in the validation procedures is given in figure 1 . A total of 179 persons reported numbness in their hand(s) at night. Of these, $134(74.8 \%)$ participated in the physical examination, together with a questionnaire-negative group of 143 persons. Information on location of current symptoms was collected in an interview at the time of the physical examination; the diagram proposed by Katz \& Stirrat (11) was used for this purpose. The physical examination evaluated the neck and upper extremities and included Phalen's test (forced wrist flexion for 1 minute) and Tinel's sign at the wrist ( 3 gentle taps over the palmar side of the wrist). The physical examinations were carried out by 1 of 2 physicians (JHA and PF), without knowledge of the answers on the questionnaire or the job of the subject. Since the workers identified at the slaughterhouse were examined in the workplace, blinding according to whether the participant was identified at the chemical plant or at the slaughterhouse was not possible. However, this group also included workers to be categorized as referents, and the case definition included neurophysiological criteria as well. In all, 61

Table 2. The slaughterhouse and its departments and processes in pig slaughtering and meat handling. The organization of the processes, time available for task completion, and mean wrist exertion (frequency of wrist movements more than $15^{\circ}$ out of neutral position in palmar or dorsal flexion or greater than $20^{\circ}$ ulnar deviation per 10 minutes (WM) and mean time proportion (\%) with wrist in positions out of neutral (TP).

\begin{tabular}{|c|c|c|c|c|c|c|c|}
\hline \multirow[t]{2}{*}{ Department } & \multirow[t]{2}{*}{ Process } & \multirow[t]{2}{*}{ Organization } & \multirow[t]{2}{*}{ Time to do the task } & \multicolumn{2}{|r|}{ WM } & \multicolumn{2}{|c|}{ TP } \\
\hline & & & & Mean & $95 \% \mathrm{Cl}$ & Mean & $95 \% \mathrm{Cl}$ \\
\hline \multicolumn{8}{|l|}{ Killing floor } \\
\hline "Dirty end" & $\begin{array}{l}\text { The pigs are received, } \\
\text { anesthetized with carbon } \\
\text { dioxide, hung by a hind } \\
\text { limb and transported by } \\
\text { conveyer to the killing site } \\
\text { and killed with a stab to the } \\
\text { throat }\end{array}$ & $\begin{array}{l}\text { The process is carried out } \\
\text { through } 9 \text { tasks, performed by } \\
1 \text { person each; } 584 \text { pigs are } \\
\text { killed every hour throughout } \\
\text { the day }\end{array}$ & About 6 seconds & . & . & & . \\
\hline "Clean end" & $\begin{array}{l}\text { The dead pigs are cut open, } \\
\text { the casings and other organs } \\
\text { are cut out, and the body is } \\
\text { halved }\end{array}$ & $\begin{array}{l}\text { The process is carried out } \\
\text { along } 2 \text { lines through } 17 \text { tasks, } \\
\text { performed by } 1 \text { person each; } \\
292 \text { pigs are slaughtered every } \\
\text { hour throughout the day }\end{array}$ & About 12 seconds & 73 & $63.1-75.5$ & 27 & $14.0-40.8$ \\
\hline Cutting floor & $\begin{array}{l}\text { The halved body is cut into } \\
\text { parts - the head, ham, loin } \\
\text { and the fore end and the } \\
\text { parts are hung on hooks }\end{array}$ & $\begin{array}{l}\text { The process is carried out } \\
\text { through } 18 \text { tasks performed by } \\
1 \text { person each; } 1080 \text { halved } \\
\text { pigs are cut by an electrical } \\
\text { saw mounted on a table every } \\
\text { hour throughout the day and } \\
\text { evening }\end{array}$ & About $3-4$ seconds & 85 & $46.0-123.2$ & 225 & $5.1-45.9$ \\
\hline Boning room & $\begin{array}{l}\text { The body parts (ham, loin } \\
\text { and fore end) from the cuting } \\
\text { floor are deboned through } \\
6 \text { to } 12 \text { complicated } \\
\text { operations }\end{array}$ & $\begin{array}{l}\text { The process is carried out by } \\
\text { the same person doing all } \\
\text { operations in the process }\end{array}$ & $1.5-5$ minutes & 56 & $48.2-63.0$ & 23 & $18.4-27.9$ \\
\hline Packing room & $\begin{array}{l}\text { The boned meat is wrapped } \\
\text { in plastic, put into cardboard } \\
\text { boxes, and weighed }\end{array}$ & $\begin{array}{l}\text { The process is carried out } \\
\text { through } 6 \text { tasks, performed by } \\
1 \text { person each }\end{array}$ & About $2-3$ seconds & 115 & $63.4-166.1$ & 119 & $6.3-32.0$ \\
\hline Casing room & $\begin{array}{l}\text { The complete set of casings } \\
\text { is divided manually and the } \\
\text { inside is turned out and } \\
\text { rinsed; the stomach and } \\
\text { casings are sorted and } \\
\text { salted }\end{array}$ & $\begin{array}{l}\text { The dividing and rinsing } \\
\text { process is carried out through } \\
6 \text { to } 8 \text { operations by } 1 \text { person; } \\
\text { the other process is carried out } \\
\text { through } 20 \text { tasks, } 1 \text { person } \\
\text { doing each; } 584 \text { casings or } \\
\text { stomachs are handled each } \\
\text { hour throughout the day }\end{array}$ & $\begin{array}{l}\text { About } 1 \text { minute } \\
\text { About } 6 \text { seconds }\end{array}$ & 76 & $52.1-99.8$ & 17 & $11.5-23.2$ \\
\hline
\end{tabular}


persons reported symptoms of nerve entrapment in the physical examination, of which 52 participated in the neurophysiological examination (figure 1). A small proportion of questionnaire-negative subjects turned out to have current symptoms indicating nerve entrapment [10 of 115 slaughterhouse workers $(8.7 \%)$ and 1 of 28 referents $(3.6 \%)]$.

\section{Neurophysiological examination}

Nerve conduction velocities across the wrist were assessed with the use of surface electrodes (12). The motor fibers were evaluated by measuring the distal onset latency across the wrist to the abductor pollices brevis muscle with the stimulating electrode just proximal to the wrist. The sensory nerve conduction velocity in the median and ulnar nerves (as reference) were assessed by measuring the antidromal onset latencies. The stimulating electrode is placed proximal to the wrist on the volar side and with the onset registered with ring electrodes placed on the proximal phalanx of the second, third, and fifth digits, respectively. The distances between the stimulating and registering electrodes were measured in millimeters with a ruler. The midpalmar skin temperature was monitored, and the hand was heated if the skin temperature was below $32^{\circ} \mathrm{C}$. The electrodiagnostic criteria for the diagnosis of median mononeuropathy was a distal motor latency of $>4.3 \mathrm{~ms}$ or a conduction velocity of $<50 \mathrm{~m} / \mathrm{s}$ for at least 1 of the sensory median finger nerves and, across the same wrist, a sensory conduction velocity of $\geq 50 \mathrm{~m} / \mathrm{s}$ in the ulnar nerve. All the tests were performed by the same trained technician, and the results were evaluated without knowledge of clinical status by a neurophysiologist (VKN). The procedure and the electrodiagnostic criteria used were standard at the Department of Neurophysiology. In all, 81 persons (figure 1) had an electrophysiological examination of a total of 97 hands (67 right and 30 left). Thirty-one of the 67 examined right hands were without symptoms in the physical examination. This group was included to establish an internal reference group for the electrophysiological measurements. The mean age of the group was 41.2 (SD 10.7) years and that of the symptom group was 39.5 (SD 9.5) years. Table 3 shows the neurophysiological results.

\section{Statistics}

Prevalence rates were calculated for CTS in bivariate models for slaughterhouse workers and in groups according to other suspected risk factors. The risk estimates were based on the prevalence ratio and have been given together with their $95 \%$ confidence intervals (95\% CI). Confounder control was performed using logistic regression analyses with the following independent variables: age [ $<35$ (reference), $35-49$, and $\geq 50$ years], wrist trauma (ever having experienced an accident to the wrist or hand), body mass index ( $<25$ (reference), $\geq 25-<30$ and $\geq 30 \mathrm{~kg} / \mathrm{m}^{2}$ ), smoking habits, gender, and medical condition. The method estimates an odds ratio, which is a good estimate of the relative risk of rare diseases (13). Risk estimates were calculated for the following 3 CTS outcomes: cases defined as (i) CTS in at least 1 hand, (ii) CTS in the dominant hand, and (iii) CTS in the nondominant hand. Adjusted risk estimates concerning positive questionnaire screening criteria for CTS were estimated using the same model. If information concerning criteria

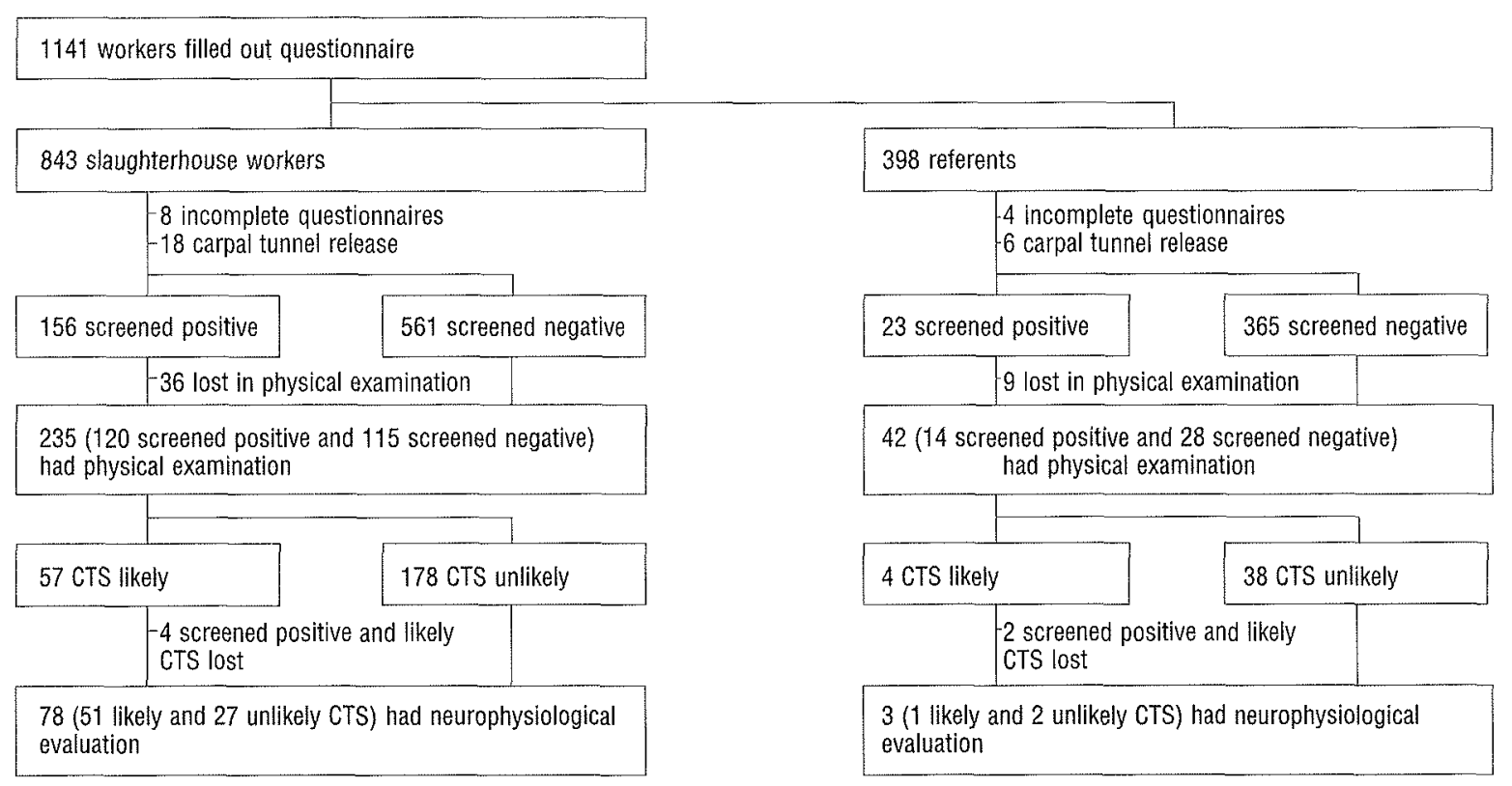

Figure 1. Flow chart - identification of subjects with carpal tunnel syndrome (CTS) and participation in procedures for validating the screening criteria. 
Table 3. Nerve conduction parameters and differences in the parameters across the wrist among persons with and without symptoms of median nerve entrapment. Distal motor latencies (DML) and sensory nerve conduction velocities (NCV) in the right median and ulnar nerves. $(\mathrm{MD}=$ mean difference, $95 \% \mathrm{Cl}=95 \%$ confidence interval)

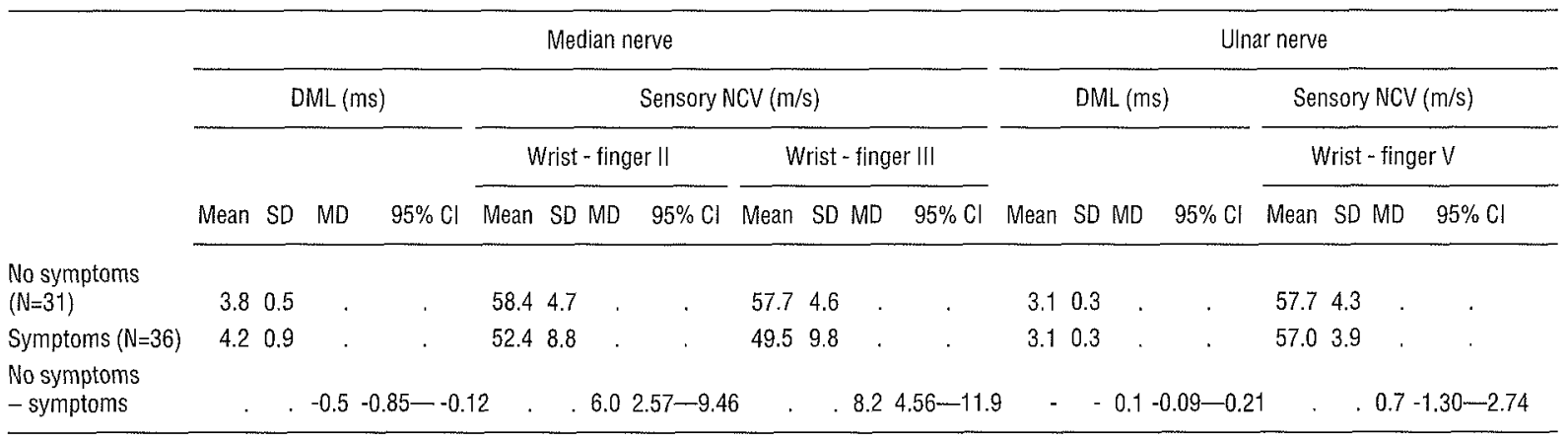

Table 4. Observed cases $(0)$, prevalence ratios (PR) and adjusted odds ratios (OR) in the multivariate logistic regression for carpal tunnel syndrome among the slaughterhouse workers (SHW). "Nondeboning slaughterhouse workers" and "deboning slaughterhouse workers" were used for the adjusted risk estimates for nonoccupational risk factors. ( $95 \% \mathrm{Cl}=95 \%$ confidence interval)

\begin{tabular}{|c|c|c|c|c|c|c|c|c|c|c|c|c|c|c|c|c|c|c|}
\hline \multirow[t]{2}{*}{ Risk factor } & \multicolumn{6}{|c|}{ Either hand } & \multicolumn{6}{|c|}{ Dominant hand } & \multicolumn{6}{|c|}{ Nondominant hand } \\
\hline & 0 & $\%$ & PR & $95 \% \mathrm{Cl}$ & OR & $95 \% \mathrm{Cl}$ & 0 & $\%$ & PR & $95 \% \mathrm{Cl}$ & $\mathrm{OR}$ & $95 \% \mathrm{Cl}$ & 0 & $\%$ & $\mathrm{PR}$ & $95 \% \mathrm{Cl}$ & OR & $95 \% \mathrm{Cl}$ \\
\hline \multicolumn{19}{|c|}{ Occupational risk factors } \\
\hline Not SHW & 6 & 1.6 & 1 & & 1 & & 4 & 1.1 & 1 & & 1 & & 30 & 0.8 & 1 & & 1 & \\
\hline $\begin{array}{l}\text { All SHW } \\
\text { Nondebon- }\end{array}$ & 44 & 6.3 & 4.01 & $1.72-9.32$ & 4.24 & $1.77-10.13$ & 22 & 3.1 & 3.01 & $1.04-8.66$ & 3.26 & $1.09-9.71$ & 30 & 4.3 & 5.471 & $1.68-17.79$ & 5.31 & $1.60-17.61$ \\
\hline ing SHW & 19 & 5.1 & 3.24 & $1.31-8.03$ & 3.25 & $1.27-8.33$ & 11 & 2.9 & 2.82 & $0.90-8.77$ & 2.90 & $0.90-9.39$ & 10 & 2.7 & 3.410 & $0.95-12.31$ & 3.01 & $0.82-11.30$ \\
\hline Deboning SHW & 25 & 7.7 & 4.882 & $2.03-11.76$ & 5.53 & $2.20-13.90$ & 11 & 3.4 & 3.22 & $1.04-10,03$ & 3.741 & $1.14-12.22$ & 20 & 6.2 & 7.822 & $2.34-26.06$ & 8.43 & $2.44-29.07$ \\
\hline Current SHW & 34 & 6.2 & 3.96 & $1.68-9.34$ & & . & . & . & 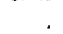 & . & . & . & . & & & . & . & . \\
\hline Former SHW & 10 & 6.6 & 4.181 & $1.55-11.29$ & . & & . & 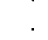 & & . & 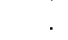 & . & . & & & . & & . \\
\hline \multicolumn{19}{|c|}{ Nonoccupational risk factors } \\
\hline \multicolumn{19}{|l|}{ Age $^{\mathrm{a}}$} \\
\hline $35-49$ years & 29 & 6.5 & 1.87 & $0.99-3.54$ & 2.30 & $1.15-4.63$ & 17 & 3.8 & 2.85 & $1.06-7.64$ & 3.24 & $1.15-9.15$ & 173 & 3.8 & 1.42 & $0.66-3.07$ & 1.82 & $0.80-4.15$ \\
\hline$\geq 50$ years & 8 & 3.2 & 0.91 & $0.38-2.17$ & 1.15 & $0.45-2.95$ & 4 & 1.6 & 1.19 & $0.32-4.38$ & 1.37 & $0.35-5.41$ & 62 & 2.4 & 0.890 & $0.33-2.42$ & 1.37 & $0.47-4.04$ \\
\hline \multicolumn{19}{|l|}{ Wrist trauma } \\
\hline Either hand & & 12.3 & 3.02 & $1.53-5.97$ & 3.87 & $1.74-8.60$ & & & & & & & & & & . & . & $\cdot$ \\
\hline $\begin{array}{l}\text { Dominant hand } \\
\text { Nondominant }\end{array}$ & d. & . & & . & & & 3 & 7.7 & 3.47 & $1.09-11.08$ & 5.141 & $1.40-18.97$ & & . & 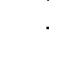 & . & & . \\
\hline hand & . & & 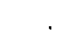 & & & & 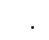 & & & & . & . & 4 & 8.7 & 3.09 & $1.14-8.44$ & 3.10 & $1.00-9.66$ \\
\hline \multicolumn{19}{|l|}{ Body mass index } \\
\hline $25-30 \mathrm{~kg} / \mathrm{m}^{2}$ & 19 & 4.7 & 1.05 & $0.59-1.88$ & 1.00 & $0.53-1.91$ & 12 & 2.9 & 1.66 & $0.72-3.81$ & 1.48 & $0.61-3.60$ & 112 & 2.7 & 0.76 & $0.37-1.57$ & 0.75 & $0.34-1.66$ \\
\hline$\geq 30 \mathrm{~kg} / \mathrm{m}^{2}$ & 6 & 5.7 & 1.29 & $0.54-3.07$ & 1.42 & $0.55-3.67$ & 4 & 3.8 & 2.15 & $0.69-6.73$ & 2.13 & $0.63-7.12$ & 2 & 1.9 & 0.54 & $0.13-2.27$ & 0.63 & $0.14-2.81$ \\
\hline Ever smoker & 35 & 4.2 & 0.71 & $0.40-1.28$ & 0.65 & $0.34-1.24$ & 16 & 1.9 & 0.49 & $0.22-1.06$ & 0.47 & $0.21-1.08$ & 23 & 2.8 & 0.700 & $0.34-1.45$ & 0.63 & $0.29-1.37$ \\
\hline Medical condition & n 5 & 7.2 & 1.62 & $0.67-3.96$ & 2.12 & $0.79-5.71$ & 3 & 4.3 & 1.91 & $0.59-6.20$ & 2.30 & $0.65-8.17$ & 3 & 4.3 & 1.460 & $0.46-4.67$ & 2.05 & $0.59-7.18$ \\
\hline Female gender & 9 & 5.5 & 1.23 & $0.61-2.49$ & 1.44 & $0.65-3.19$ & 4 & 2.4 & 1.02 & $0.36-2.92$ & 1.13 & $0.36-3.57$ & 8 & 4.9 & 1.800 & $0.82-3.91$ & 2.20 & $0.91-5.30$ \\
\hline
\end{tabular}

a Reference group: age less than 35 years.

beference group: BMl less than $25 \mathrm{~kg} / \mathrm{m}^{2}$.

Table 5. Observed cases (0), prevalence ratios (PR), and adjusted odds ratios $(\mathrm{OR})$ for carpal tunnel syndrome and cumulative exposure.

\begin{tabular}{lrccccc}
\hline $\begin{array}{l}\text { Years of } \\
\text { exposure }\end{array}$ & 0 & $\%$ & $\mathrm{PR}$ & $95 \% \mathrm{Cl}$ & $\mathrm{OR}$ & $95 \% \mathrm{Cl}$ \\
\hline 0 & 6 & 1.6 & & & & \\
$1-5$ & 7 & 4.8 & 3.04 & $1.04-8.91$ & 3.57 & $1.13-11.34$ \\
$6-10$ & 16 & 7.6 & 4.84 & $1.92-12.18$ & 5.34 & $2.01-14.20$ \\
$11-15$ & 8 & 5.7 & 3.60 & $1.27-10.20$ & 3.29 & $1.10-9.83$ \\
$16-20$ & 4 & 7.1 & 4.54 & $1.32-15.57$ & 4.18 & $1.11-15.80$ \\
$>20$ & 9 & 6.3 & 3.97 & $1.44-10.95$ & 4.44 & $1.49-13.22$ \\
\hline
\end{tabular}

a The odds ratios were based on a logistic regression controlling for age, gender, accident to the wrist, body mass index, smoking, medical conditions, and current exposure. defining CTS was missing, the person in question was excluded from the analysis $(\mathrm{N}=63)$. If values concerning body mass index or smoking habits were missing, the person was classified as the least (or not) exposed to these potential risk factors. Risk estimates concerning nonoccupational factors were adjusted using the 2 groups of slaughterhouse workers in the model. To evaluate whether the risk for CTS increased with cumulative exposure, the slaughterhouse workers were divided into 5 exposure groups according to their duration as a slaughterhouse worker $(1-5,6-10,11-15,16-20$ and $>20$ years) and compared with the reference group. Adjusted risk 
estimates for CTS (in either hand) were calculated by multivariate logistic regression using the same independent variables in the model plus prestudy employment status as a proxy for current exposure.

\section{Results}

All together $50(4.6 \%)$ persons with CTS were identified. Table 4 shows the number of cases grouped according to occupational and nonoccupational risk factors and a comparison of the prevalence of CTS (either hand), CTS in the dominant hand, and CTS in the nondominant hand, together with the adjusted risk estimates. The crude prevalence of CTS in either hand was higher for the slaughterhouse workers independent of current exposure status, and the prevalence was increased for both groups of slaughterhouse workers, but to a greater extent for workers with deboning tasks. This difference was mainly caused by an increased prevalence of CTS in the nondominant hand, while the prevalence of CTS in the dominant hand was increased to about the same extent in both groups of slaughterhouse workers. The prevalence of CTS was increased in the age group of 35-49 years and among persons who had experienced an earlier wrist trauma. Control for these and other possible confounders did not alter the risk estimates (table 4 ). The prevalence rates and adjusted risk estimates for CTS in the groups are shown table 5 according to duration of exposure. There was an increasing risk according to cumulative exposure up to 6 to 10 years, after which the risk stayed almost constant, at a slightly lower level.

The adjusted odds ratio for positive questionnaire screening criteria was 4.31 (95\% CI 2.60-7.14) for the slaughterhouse workers without deboning tasks and 5.79 (95\% CI 3.47-9.64) for deboning slaughterhouse workers.

\section{Discussion}

Our observation of an elevated risk for CTS, as defined in this study, among slaughterhouse workers supports the hypothesis that exposure to combined forceful and repetitive manual movements is a risk factor for CTS. Furthermore, we observed an increased risk for CTS in the nondominant hand among slaughterhouse workers with deboning tasks and a tendency towards increasing risk according to cumulative exposure up to 6 to 10 years. Thereafter, the risk appeared constant but at a lower level. These observations suggest that both the level and duration of exposure is of importance in the provocation of CTS. The ergonomic observations of the right wrist showed that working as a slaughterhouse worker implies repetitive movements and work in nonneutral postures a substantial part of the time. Mean force requirements on the forearm flexor $(\mathrm{N}=45)$ muscles while deboning has been assessed by electromyography (14), which showed a static activity $(\mathrm{P}=0.1)$ of between $8 \%$ and $9 \%$, a median activity $(\mathrm{P}=0.5)$ of between $25 \%$ and $30 \%$, and a peak activity ( $\mathrm{P}=0.90)$ of about $60 \%$ of a mean maximal hand grip of $54.6 \mathrm{~kg}$. In an evaluation of force requirements (15) in worktasks designed to simulate combined highforce and high repetition exposure, the corresponding values were $1.5 \%, 19.1 \%$, and $69.5 \%$, respectively, for 6 subjects. Slaughterhouse workers performing deboning assist constantly and actively with the nondominant hand in tearing, lifting, turning, and holding the $6-12 \mathrm{~kg}$ body parts. Although slaughterhouse workers performing other tasks also do bimanual work, the impression gained from a plant walk-through was that levels of exertion on the nondominant hand was considerably lower in the nondeboning group, but no detailed ergonomic observation of the nondominant hand was performed. However, in a study of 3 Swedish slaughterhouse workers performing deboning, force requirements were assessed from EMG recordings from both the left and right short flexor carpi radialis muscles during at least 6 hours of work. It was observed that the muscle on the left side was exposed to a much higher level than the right, holding the knife (17). An unusual clustering of left-sided CTS has also been reported among Finnish slaughterhouse workers slaughtering cows (16). It was proposed that tearing and holding with the left hand may have contributed to this clustering.

Certain factors may have affected the validity of our observations. There was a greater participation rate for the workers identified at the slaughterhouse and for the slaughterhouse workers. No differences were observed in age, seniority, or gender distribution, and telephone interviews of 117 nonparticipants revealed no major health-associated selection into the study, either among the slaughterhouse workers or the referents. In the reference group the rate of participation in the physical and neurophysiological examinations was smaller, and therefore the possibility of the referents receiving a CTS diagnosis was reduced. However, the prevalence of CTS among the 11 nonparticipants in the reference group would need to be much higher than among the 40 nonparticipating slaughterhouse workers to alter the risk estimates, and the adjusted risk estimates with positive screening criteria as the dependent outcome showed similar results.

The exposure groups were formed on the basis of information concerning jobs held at the slaughterhouse and a contrast between slaughterhouse workers and chemical workers performing supervising and, at times, light manual work. The aim was to obtain a reference group 
that was comparable with slaughterhouse workers except for the suspected risk factor studied. The questionnaire showed large, though not complete contrast in the answers concerning involvement with repetitive work. If the answers concerning hand exposures among the referents reflected the same level of hand exposure as among the slaughterhouse workers, then the risk of CTS in relation to hand intensive work would have been negatively biased. When underlying exposures are measured using job titles $(7,18-20)$, misclassification can occur from differences in the underlying exposure (force, repetitivity, level, duration of exposure, vibration) among persons with the same job title. Indirect exposure classification based on, for example, ergonomic observations $(21,22)$ leaves the question open of which types of jobs are being categorized whether the measured exposures are of more relevance than the unmeasured ones. Since it is not known which ergonomic measures are the most important for developing diseases, an exposure description should include both task descriptions and the ergonomic characteristics of the tasks so that the best description of the level of integrated exposure can be obtained. In our study ergonomic observations of the dominant hand revealed low variation in exposure between slaughterhouse workers from the different departments; this finding is in agreement with the observed equally increased risk of CTS in the dominant hand. Ergonomic observations of the nondominant hand would aid interpretation of the observed increased risk of CTS in the nondominant hand among the deboning workers.

There is no standard definition for CTS. Our definition included former carpal tunnel release. Whether a neurophysiological evaluation was done before the operation or the operation was based on clinical judgment was not known. A less precise diagnosis seems to be more likely among persons who have been operated on, and therefore some misclassification may be introduced. CTS and other upper-extremity symptoms may be modified by occupational manual exposures. Among exposed subjects, this possibility may lead to an earlier need for treatment given the same degree of CTS, causing positive detection bias. This occurrence could certainly be a problem, in particular in case-referent design, when cases are identified in occupational health settings. However, relatively more of the CTS cases in the reference group were classified according to the carpal tunnel release criteria, and exploring this threat to validity in other studies (7) gave no support to such bias.

Other studies have defined CTS by different criteria, for example, by symptoms in combination with positive tests in a physical examination (21) or neurophysiological criteria alone $(18,19)$, or by a combination of symptoms, signs, and electrophysiological criteria for CTS. This variation results in large differences in the prevalence of what is called CTS [from $0.6 \%$ (21) to $28 \%$ (18) among unexposed persons and from 5.5\% and up to $61 \%$, respectively, in the highest exposure groups in the same 2 studies]. Clinical diagnostic tests are not valid in predicting impaired nerve conduction of the median nerve across the carpal tunnel $(23,24)$. Although using the same name for the disease, the criteria differ among studies and so does the prevalence. Our definition of CTS was constructed to reflect what can be called a common clinical consensus of what is usually understood as CTS (25). The positive neurophysiological criteria of nerve entrapment were chosen to fit this consensus. Our electrophysiological evaluation of 31 healthy hands seemed to support both the chosen cut point for defining disease and the possibility that CTS symptoms, as assessed in a physical examination, are valid in identifying subjects with impaired nerve function across the wrist.

In spite of the drawbacks of our study and their possible influence on the validity of the results, which in our opinion probably underestimated the risk, we found that the results of this study support the hypothesis that handintensive work, as seen at a Danish slaughterhouse, is a risk factor for developing CTS. Because of similarities in meat processing in other countries $(26,27)$, this conclusion can probably be generalized.

\section{Acknowledgments}

The authors would like to thank the Danish Working Environment Fund, which funded the study.

Hanne Christensen, Birgit Juul Christensen, Duco van Lelieveld, and Jakob Larsen from the Department of Physiology, National Institute of Occupational Health, Copenhagen, for conducting the ergonomic exposure assessments, and technician Lotte Faarbæk, who conducted the neuronographic tests.

\section{References}

1. Dieck GS, Kelsye JL. An epidemiologic study of carpal tunnel syndrome in an adult female population. Prev Med 1985;14:63-9.

2. Posch JL, Marcotte DR. Carpal tunnel syndrome: an analysis of 1,201 cases. Orthop Rev 1976; V:25-35.

3. Hjøllund NHI, Bonde JPE. Kan karpaltunnelsyndrom være arbejdsbetinget [Can the carpal tunnel syndrome be occupationally induced]? Ugeskr Læger 1992;154:2968—74.

4. Hagberg M, Morgenstern H, Kelsh M. Impact of occupations and job tasks on the prevalence of carpal tunnel syndrome [review]. Scand J Work Environ Health 1992;18:337—45.

5. Stock SR. Workplace ergonomic factors and the development of musculoskeletal disorders of the neck and upper limbs: a meta-analysis. Am J Ind Med 1991;19:87-107.

6. Wieslander G, Norbäck D, Göthe C-J, Juhlin L. Carpal tunnel 
syndrome (CTS) and exposure to vibration, repetitive wrist movements, and heavy manual work: a case referent study. $\mathrm{Br}$ $\mathrm{J}$ Ind Med 1989;46:43-7.

7. Rossingnol M, Stock S, Patry L, Armstrong B. Carpal tunnel syndrome: what is attributable to work? The Montreal study. Occup Environ Med 1997;54:519-23.

8. Checkoway H, Pearce N, Dement JM. Design and conduct of occupational epidemiology studies: I. design aspects of cohort studies. Am J Ind Med 1989;15:363-73.

9. Stockholm MUSIC 1 Study Group. Frågeformulär som använts i Stockholm MUSIC 1 [Questionnaires used by Stockholm MUSIC 1]. Stockholm: Music Books, 1990.

10. Christensen $\mathrm{H}$, Holmboe $\mathrm{K}$, Juul-Kristensen B, van Lelieveld D, Søgaard K, Hansen ÅM. Arbejdspladsunders $ø$ gelse [Workplace study]. In: Christensen H, editor. Udbeningsarbejde svineslagterier [Deboning at pig slaughterhouses]. Copenhagen: National Institute of Occupational Health, 1996:33-66.

11. Katz JN, Stirrat CR. A self-administered hand diagram for the diagnosis of carpal tunnel syndrome. J Hand Surg 1990;15A:360-3.

12. DeLisa JA, Lee HJ, Baran EM, Lai K-S, Spielholtz N. Manual of nerve conduction velocity and clinical neurophysiology. 3rd ed. New York (NY): Raven Press, 1994.

13. Greenland $S$, Thomas DC. On the need for the rare disease assumption in case-control studies. Am J Epidemiol 1982;116:547-53.

14. Christensen H, Larsen J. Handgrip strength and forearm muscle activity during meat cutting. In: PREMUS 95. Books of abstracts. Montreal: Institut de recherche en santé et en sécurité du travail du Québec (IRSST), 1995:72—4.

15. Moore A, Wells R, Ranney D. Quantifying exposure in occupational manual tasks with cumulative trauma disorder potential. Ergonomics 1991;12:1433-53.

16. Hagberg M, Jonsson B, Brundin L, Ericson B-E, Örtelius A Besvär från rörelseorganen bland stykare: en epidemiologisk, ergonomisk och elektromyografisk studie [An epidemiologic, ergonomic and electromyographic study of musculo-skeletal complaints among meat-cutters]. Stockholm: Arbetarskyd- dverket, 1983:1—52. Arbete och Hälsa, 12.

17. Falck B, Aarnio P. Left-sided carpal tunnel syndrome in butchers. Scand J Work Environ Health 1983;9:291-7.

18. Schottland JR, Kirschberg GJ, Fillingim R, Davis VP, Hogg F. Median nerve latencies in poultry processing workers: an approach to resolving the role of industrial "cumulative trauma" in the development of carpal tunnel syndrome. I Occup Med 1991;33:627-31.

19. Nathan PA, Meadows KD, Doyle LS. Occupation as a risk factor for impaired sensory conduction of the median nerve at the carpal tunnel. J Hand Surg 1988;13-B:167-70.

20. Punnet L, Robins JM, Wegman DH, Keyserling WM. Soft tissue disorders in the upper limbs of female garment workers. Scand J Work Environ Health 1985;11:417-25.

21. Silverstein BA, Fine LJ, Armstrong TJ. Occupational factors and carpal tunnel syndrome. Am J Ind Med 1987;11:343--58.

22. Barnhart S, Demers PA, Miller M, Longstreth WT Jr, Rosenstock L. Carpal tunnel syndrome among ski manufacturing workers. Scand J Work Environ Health 1991;17:46-52.

23. De Krom MCTFM, Knipschild PG, Kester ADM, Spaans F. Efficacy of provocative tests for diagnosis of carpal tunnel syndrome. Lancet 1990;335:393-5.

24. Katz JN, Larson MG, Sabra A, Krarup C, Stirrat CR, Sethi R et al. The carpal tunnel syndrome: diagnostic utility of the history and physical examination findings. Ann Intern Med 1990;112:321-7.

25. Krom MCTFMde, Kester ADM, Knipschild PG, Spaans F. Risk factors for carpal tunnel syndrome. Am J Epidemiol 1990;132:1102-10.

26. Moore JS, Garg A. Upper extremity disorders in a pork processing plant: relationships between job risk factors and morbidity. Am Ind Hyg Assoc J 1994;55:703-15.

27. Maeser VR, Hayes JM, Hyde AG. An industrial cause of carpal tunnel syndrome. J Hand Surg 1986;11-A:222-7.

Received for publication: 28 July 1997 